School of Finance

University of St.Gallen

ANNOUNCEMENTS OF INTEREST RATE FORECASTS: DO POLICYMAKERS STICK TO THEM?

NiKola MiRKov

GISLE JAMES NATVIK

WORKING PAPERS ON FinANCE No. 2013/3

SWISS INSTITUTE OF BANKING AND FINANCE (S/BF - HSG)

APRIL 2013 


\title{
Announcements of Interest Rate Forecasts: Do Policymakers Stick to Them?*
}

\author{
Nikola Mirkov ${ }^{\dagger}$ \\ Universität St.Gallen
}

\author{
Gisle James Natvik \\ Norges Bank
}

\author{
First Draft: March 2012 \\ This Version: April 2013
}

\begin{abstract}
If central banks value the ex-post accuracy of their forecasts, previously announced interest rate paths might affect the current policy rate. We explore whether this "forecast adherence" has influenced the monetary policies of the Reserve Bank of New Zealand and the Norges Bank, the two central banks with the longest history of publishing interest rate paths. We derive and estimate a policy rule for a central bank that is reluctant to deviate from its forecasts. The rule can nest a variety of interest rate rules. We find that policymakers appear to be constrained by their most recently announced forecasts.
\end{abstract}

Keywords: Interest rates, forecasts, Taylor rule, adherence

JEL Classifications: E43, E52, E58

\footnotetext{
${ }^{*}$ We are most grateful to Francesco Ravazzolo, Dagfinn Rime and Anders Vredin for insightful discussions at the early stage of the project. A great thanks to Glenn Rudebusch, Francis Diebold, Paul Söderlind, Alejandro Justiniano, Monika Piazzesi, Refet Gürkaynak, Bart Hobijn, Ian DewBecker, Rhys Bidder, Paul Hubert, Daniel Kienzler, Øistein Røisland, Kevin Lansing, Snorre Evjen, Mathis Mehlum and the seminar and conference participants at the Norges Bank, Universität St.Gallen, Stanford University, Federal Reserve Bank of San Francisco, International Symposium on Forecasting 2012, and the 44th Money, Banking and Finance Conference. Views expressed in this paper are those of the authors, and do not necessarily reflect those of Norges Bank.

${ }^{\dagger}$ Nikola Nikodijevic Mirkov (corresponding author), Universität St.Gallen, Rosenbergstr. 52, 9000 St.Gallen, Switzerland, E-mail: mirkov@stanford.edu, Tel: +1 4156974137

${ }^{\ddagger}$ Gisle James Natvik, Norges Bank, Bankplassen 2, 0151 Oslo, Norway, E-mail: gislejames.natvik@norges-bank.no, Tel: +4722 316338
} 


\section{Introduction}

According to economic theory, monetary policy predominantly affects the economy through expectations regarding the future path of short-term interest rates. ${ }^{1}$ This insight takes center stage in the debate on "forward guidance" and has motivated a number of central banks to communicate their policy intentions explicitly by publishing their own forecasts of future interest rates. ${ }^{2}$ However, the practice of announcing policy intentions has long been somewhat controversial, and a key issue is whether past announcements could constrain future policy decisions, ${ }^{3}$ and what the normative implications of such a constraint might be. The reduced flexibility could prevent sufficiently strong policy responses to macroeconomic shocks. On the other hand, the effectiveness of forward guidance requires that the central bank eventually implements the signaled policy and does not simply provide a view on the likely future path of the economy. ${ }^{4}$ Importantly, even though there is a rich theoretical debate on the desirability of announcing interest rate forecasts, the empirical evidence on whether past announcements actually influence future policy is scarce. Our paper attempts to close this gap.

We derive a simple policy rule for a central bank that perceives deviations from its previously announced forecasts to be costly and therefore has an incentive to stick to them. The specification is sufficiently flexible to nest a broad class of interest rate rules proposed elsewhere in the literature. We may therefore use a host of alternative policy formulations to separate the movements in the central bank's "preferred" policy rate, i.e. movements in the policy instrument driven by the bank's usual response to changes in the economy, from the effect of previously published interest rate forecasts. The rules are estimated on the actual policy rates of the Reserve Bank of New Zealand (RBNZ) and the Central Bank of Norway (Norges Bank) to answer the big question: do announced forecasts influence actual policy decisions? To the best of our knowledge, we are the first to address this question.

\footnotetext{
${ }^{1}$ See Eggertsson and Woodford (2004) and Woodford (2005).

${ }^{2}$ The Reserve Bank of New Zealand inaugurated the practice (in 1997), followed by the Central Bank of Norway, Norges Bank, (in 2005), the Swedish Riksbank and the Central Bank of Iceland (in 2007), the Czech National Bank (in 2008) and the Federal Reserve (in 2012).

${ }^{3}$ See for instance Svensson (2009), Mishkin (2004), Goodhart (2009) and Kohn (2008). Another debated issue concerns the merits of informing private agents about the central bank's reaction pattern, see for example Morris and Shin (2002), Svensson (2006), Gosselin, Lotz and Wyplosz (2008) and Rudebusch and Williams (2008).

${ }^{4}$ See Woodford (2012) and Gersbach and Hahn (2011).
} 
The work that most resembles our analysis is Campbell, Evans, Fisher and Justiniano (2012), who incorporates qualitative forward guidance (e.g., "considerable period" language) in the reaction function of the Fed and show that the extended policy rule offers improved empirical predictions. In contrast to our approach, however, the authors do not examine quantitative forward guidance and do not assume that the Fed faces costs from deviating from it. Their assumption is that the public knows that the Fed will renege on such "promises" in the future, as the policy rule describes its preferred behavior. ${ }^{5}$

Our main result suggests that both the RBNZ and Norges Bank are reluctant to deviate from previously announced interest rate forecasts when setting their policy rates. Specifically, the two central banks appear constrained by their 1quarter-ahead forecast announced in the quarter before the actual decision takes place. The forecasts older than one quarter have no effect on the current policy rate. The result holds both when we model the preferred policy rate using estimated rules, and when we approximate it using the central banks' "nowcasts" of the policy rate published in the monetary policy reports. Finally, we show that policy rules augmented to allow for forecast adherence explain several episodes in the behaviors of the two banks much better than policy rules without interest rate forecasts.

We perform two robustness checks of the main result. First, we ask whether our empirical strategy "cries wolf" i.e., whether simple policy rules tend to indicate forecast adherence, when the policymaker has no such preferences. To this end, we use a basic New Keynesian model from Gersbach and Hahn (2011) to simulate the optimal behavior of a central bank that minimizes a loss function with a weight on forecast errors. The model is simulated for different values of the weight to mimic different degrees of preference towards forecast adherence. We then apply our empirical strategy to simulated data and show that the estimated policy rules do not lead us to commit false positive errors: the estimated coefficient on forecasts is positive and significant only if the central bank has a sufficiently strong desire to reduce forecast deviations.

\footnotetext{
${ }^{5}$ The authors refer to such forward guidance as "Odyssean" forward guidance, as it resembles Odysseus commanding his sailors to tie him to the ship's mast, so that he can enjoy the Sirens' song without jumping overboard.
} 
Second, we discuss whether our results can be explained by a completely different assumption regarding policymakers' preferences, namely that the two central banks minimize surprises in the policy rate, as suggested by Svensson (2003). ${ }^{6}$ We argue that our results would only be consistent with such preferences if we assume that: 1) the central bank's forecasts and market expectations of future short-rates are perfectly aligned; 2) the central bank adopts market expectations as its own. We conjecture that the second assumption is unlikely, given the lack of evidence of such behavior. In addition, we run a "placebo test" on the Norges Bank data before it began publishing interest rate forecasts, and show that a previous quarter 3-month forward rate, as a proxy for market expectations, had no effect on the policy rate. ${ }^{7}$

The reminder of the paper is organized as follows. In Section 2, we discuss the dataset and the institutional setting in which the two central banks announce interest rate forecasts. Section 3 provides details on our estimation strategy. Section 4 reports the main results and illustrates the robustness checks we perform.

\section{Dataset on Interest Rate Forecasts}

\subsection{Reserve Bank of New Zealand}

The Reserve Bank of New Zealand (RBNZ) was the first central bank to publish its own interest rate forecasts, together with projections for CPI inflation and GDP growth. Beginning in March 1997, the forecasts for the 90-days Bank Bill rate have been published in the quarterly Monetary Policy Statement (MPS), and the upper panel of Figure 1 illustrates an example from the June 2012 MPS. The RBNZ only publishes the central forecast, and in addition it provides a qualitative assessment of "what the RBNZ sees as the main risks and uncertainties around the central forecast." ${ }^{8}$ Starting with the MPS of June 2003, the Bank has published both the current and previous quarter projections as Figure 1 shows.

\section{FIGURE 1 ABOUT HERE}

\footnotetext{
${ }^{6}$ For an insightful discussion of such preferences, see Rudebusch (2006).

${ }^{7}$ We are unable to perform the placebo test for the RBNZ, since its operational procedures were significantly changed at the beginning of our sample in March 1999.

${ }^{8}$ See Drew and Karagedikli (2008).
} 
The main tool used to produce all of the forecasts is the RBNZ's core macroeconomic model, ${ }^{9}$ where the policy rate is set according to a forward-looking Taylor rule. Interest rate forecasts are conditional on the RBNZ's projections of future inflation, and the mechanism for producing those forecasts is referred to as the endogenous policy forecast system. ${ }^{10}$ Finally, the model-based forecasts are subject to a considerable amount of judgment before ultimately being released in the MPS. ${ }^{11}$ The Bank's interest rate forecasts cover an 8-quarter horizon, and the upper panel of Figure 2 illustrates the 1-, 2- and 3-quarters ahead forecasts over time against the realized 90-day Bank Bill rate. The start date for the analysis of the New Zealand data is March 1999, when the RBNZ adopted the Official Cash Rate (OCR) system, and the operating procedures of the RBNZ have remained broadly unchanged since.

\subsection{Norges Bank}

Three times a year, usually in March, June and October, the Central Bank of Norway publishes its Monetary Policy Report (MPR), which includes projections of the future key policy rate, CPI inflation, the output gap and CPI inflation that excludes changes in tax and energy prices. ${ }^{12}$ All of the forecasts are published in the form of fan charts, illustrated in the lower panel of Figure 1. The reason for publishing central forecasts together with confidence bands is to emphasize the contingency of those forecasts. ${ }^{13}$

\section{FIGURE 2 ABOUT HERE}

The main tool for producing interest rate forecasts is the core macroeconomic model of the Norges Bank, NEMO, combined with judgment. ${ }^{14}$ The model-generated forecasts are conditional on key macroeconomic projections, various exogenous variables (e.g., government spending, oil investments) and financial market infor-

\footnotetext{
${ }^{9}$ The most recent available documentation on this model is Benes, Binning, Fukac, Lees and Matheson (2009).

${ }^{10}$ See Ranchhod (2002).

${ }^{11}$ See Drew and Karagedikli (2008).

${ }^{12}$ As of 2013, Norges Bank will publish its path four times a year.

${ }^{13}$ See Holmsen, Qvigstad, Røisland and Solberg-Johansen (2008).

${ }^{14}$ The Norwegian Economy Model (NEMO), a medium-size DSGE model, has been used for policy making since 2008 and details can be found in Brubakk, Husebø, Maih, Olsen and Magne (2006). For a discussion of the use of judgment, see Holmsen et al. (2008).
} 
mation, and derived under the condition that the interest rate is set to minimize a loss function over macroeconomic outcomes. At this stage, Norges Bank staff follows a set of three criteria for "appropriate" interest rate forecasts: 1) achievement of the inflation target; 2 ) a reasonable balance between inflation and capacity utilization; 3) robustness. These criteria are reflected by the loss function that is minimized subject to the NEMO model equations. Finally, the Executive Board decides on the likely interval for the policy rate over the next three months (the "strategy interval"), and the staff produces a forecast for the interest rate path. ${ }^{15}$ The lower panel of Figure 2 plots the point interest rate forecasts (solid lines) for the period from August 2006 to December 2011 together with the realized key policy rate (dashed line).

\section{Model of Interest Rate Adherence}

\subsection{Deriving the Reaction Function}

Consider a policymaker who at each time $t$ sets the current interest rate $i_{t}$ and announces a future path of that rate. The path consists of interest rate forecasts for a number of consecutive periods in the future, given the central bank's expectations regarding future macroeconomic variables, such as inflation or unemployment. We assume that the central bank only publishes two such interest rate forecasts, a short-horizon forecast $i_{t, t+s}^{p}$ (e.g., 1 quarter) and a long-horizon forecast $i_{t, t+l}^{p}$ (e.g., 8 quarters). In this way, we attempt to keep the exposition simple, while mimicking the cross-section of published interest rate forecasts. The Bank sets $i_{t}$, $i_{t, t+s}^{p}$ and $i_{t, t+l}^{p}$ in every $t$ to minimize the expected discounted sum of future per period losses:

$$
\mathscr{L}_{t}=\frac{1}{2} E_{t} \sum_{k=0}^{\infty} \delta^{k}\left[\begin{array}{c}
\left(i_{t+k}-i_{t+k}^{*}\right)^{2}+\varphi\left(i_{t+k}-i_{t+k-1}\right)^{2} \\
+\kappa_{s}\left(i_{t+k}-i_{t+k-s, t+k}^{p}\right)^{2}+\kappa_{l}\left(i_{t+k}-i_{t+k-l, t+k}^{p}\right)^{2}
\end{array}\right]
$$

The first term in the loss function represents the costs of deviating from an implied target level of the policy rate. The target rate $i_{t}^{*}$ summarizes the central bank's preferences and the state of the economy in period $t$, and can be any non-inertial

\footnotetext{
${ }^{15}$ For further details on the process, see Alstadheim, Bache, Holmsen, Maih and Røisland (2010).
} 
Taylor rule with arbitrarily numerous forward- and backward-looking variables. Note that this method of deriving a policy rule is different from characterizing the policy that minimizes a loss function over intermediate targets such as inflation and output. The latter strategy requires the specification of an economic model, which implies that the resultant policy formulation will be model dependent, and any estimation based on it will be sensitive to model misspecification. Our approach is less model-specific, as it allows us to estimate a variety of $i_{t}^{*}$.

The second term in the per-period loss function captures policymakers' preference for interest rate smoothing. The parameter $\varphi$ results in policy inertia. ${ }^{16}$

Our key objects of interest are the last two terms in the loss function, where $\kappa_{s}$ and $\kappa_{l}$ capture the policymaker's preference for adhering to previously announced interest rate forecasts. If either of these weights is positive, the policymaker perceives forecast deviations as costly and tries to minimize the distance between the current interest rate and the previously announced forecasts for the current period. In this respect, our setting is similar to Gersbach and Hahn (2011). The difference is that we allow for a cross-section of forecasts, as the central banks publish multiple period forecasts, and more importantly, might value the accuracy of forecasts from different horizons differently.

The first order condition for the optimal interest rate $i_{t}$ is given by:

$$
\begin{gathered}
i_{t}-i_{t}^{*} \\
+\varphi\left(i_{t}-i_{t-1}\right)-\delta \varphi\left(E_{t} i_{t+1}-i_{t}\right) \\
+\kappa_{s}\left(i_{t}-i_{t-s, t}^{p}\right)+\kappa_{l}\left(i_{t}-i_{t-l, t}^{p}\right)-E_{t} \sum_{k=0}^{\infty} \delta^{k}\left[\left(i_{t+k}-i_{t+k}^{*}\right) \frac{\partial i_{t+k}^{*}}{\partial i_{t}}\right]=0
\end{gathered}
$$

The term $E_{t} \sum_{k=0}^{\infty} \delta^{k}[\bullet]$ implies that deviations from the target rate might affect the target rate itself, by affecting the macroeconomic variables contained in $i_{t}^{*}$. Yet, as monetary policy influences the economy with a lag, the current policy rate decisions have a negligible effect on the $i^{*}$ in the short term, i.e., $\frac{\partial i_{t+k}^{*}}{\partial i_{t}} \approx 0$ when $k$ is small. For a sufficiently large $k$, the actual policy rate should converge to the target rate, and thus $E_{t}\left(i_{t+k}-i_{t+k}^{*}\right) \approx 0$ when $k$ is large. Approximatively, the product $E_{t}\left(i_{t+k}-i_{t+k}^{*}\right) \frac{\partial i_{t+k}^{*}}{\partial i_{t}} \approx 0$ for all $k=1,2, \ldots, T$. Imposing these approximations and solving the equation (2) for the current interest rate yields a testable

\footnotetext{
${ }^{16}$ See for instance Clarida, Galí and Gertler (2000) and Bache, Røisland and Torstensen (2011).
} 
specification of the reaction function:

$$
i_{t}=\Omega^{*}\left[\begin{array}{lllll}
1 & \varphi & \delta \varphi & \kappa_{s} & \kappa_{l}
\end{array}\right]\left[\begin{array}{c}
i_{t}^{*} \\
i_{t-1} \\
E_{t} i_{t+1} \\
i_{t-s, t}^{p} \\
i_{t-l, t}^{p}
\end{array}\right]
$$

where

$$
\Omega^{*}=\frac{1}{1+\varphi(1+\delta)+\kappa_{s}+\kappa_{l}}
$$

measures the responsiveness of the actual policy rate $i_{t}$ to changes in the macroeconomic environment. Intuitively, the reluctance to deviate from previously published interest rate forecasts, i.e. a positive $\kappa_{j}$ for $j=\{s, l\}$, reduces the impact of changes in $i_{t}^{*}$ on the actual policy rate in a manner similar to the effect of interest rate smoothing. Therefore, forecast adherence will dampen the responsiveness to macroeconomic innovations. When $\kappa_{j}=0$ for $j=\{s, l\}$, equation (3) collapses to:

$$
i_{t}=\left(1-\rho_{b}-\rho_{f}\right) i_{t}^{*}+\rho_{b} i_{t-1}+\rho_{f} E_{t} i_{t+1}
$$

where

$$
\rho_{b}=\frac{\varphi}{(1+\varphi(\delta+1))}, \quad \rho_{f}=\delta \frac{\varphi}{(1+\varphi(\delta+1))}
$$

and a preference for interest rate smoothing implies both partial adjustment from the previous policy rate, and adjustment to the anticipated policy rate in the next period, as shown in Bache et al. (2011). Accounting for the forward-looking aspect of interest rate smoothing is essential in our setting, where we attempt to isolate the adherence to previously announced forecasts from the policymaker's effort to anticipate the next policy rate level.

We next proceed from the general formulation of the reaction function in equation (3) to establish various policy rules that can be estimated for the two central banks, the RBNZ and the Norges Bank, to identify the adherence preferences $\kappa_{j}$ for $j=$ $\{s, l\}$. 


\subsection{Policy Rules}

The main challenge in identifying $\kappa_{j}$ for $j=\{s, l\}$ is to capture the empirical counterpart of the implied target rate $i_{t}^{*}$. We follow the available documentation provided by the two banks, staff memos and the general literature on simple policy rules to ensure a solid fit of the $i_{t}^{*}$ before adding the interest rate forecasts. The following section describes the reaction functions we estimate.

\subsubsection{Institution-specific Rules}

For each central bank, we follow the documentation on simple policy rules that describes the actual policy reasonably well. Both policymakers are assumed to apply a partial adjustment to the target rate.

For the RBNZ, we follow the definition of the target rate from the last available macro-model used for policy purposes, the so called K.I.T.T. ${ }^{17}$ The target rate is defined as

$$
i_{t}^{*}=\gamma^{\pi}\left(E_{t} \pi_{t+1}-E_{t} \bar{\pi}_{t+1}\right),
$$

where $E_{t} \pi_{t+1}$ is the next period inflation expectation and $E_{t} \bar{\pi}_{t+1}$ is the expected target inflation rate. The terms on the right-hand side are demeaned. For the inflation expectations, we use the RBNZ survey of inflation expectations 2 years ahead. ${ }^{18}$ For the Norges Bank, we follow Bernhardsen (2008), who argues that the following target rate is both policy-relevant and fits the historical record well:

$$
i_{t}^{*}=\gamma^{\pi} \pi_{t}+\gamma^{i n t} i_{t}^{i n t}+\gamma^{w} w_{t}+\gamma^{y} y_{t}
$$

Here $\pi_{t}$ is core inflation, and the series is constructed by averaging the year-onyear monthly increase in the CPI index adjusted for energy and taxes within each

\footnotetext{
${ }^{17}$ Kiwi Inflation Targeting Technology, see Benes et al. (2009).

${ }^{18}$ Great thanks to Ashley Lienert from the RBNZ for providing these data. We should also mention at this point that we attempted to use the one-quarter-ahead inflation forecasts from the Monetary Policy Statement as inflation expectations. As the forecasts consider headline inflation, the series is noisy and the $\gamma^{\pi}$ coefficient turns out to be insignificant.
} 
quarter. The series is also seasonally adjusted. Further, $i_{t}^{\text {int }}$ is the international interest rates index (quarterly average). The index is constructed by weighting the interest rate levels of Norway's main trading partners using trade data weights. ${ }^{19}$ The next term, $w_{t}$, is year-on-year wage growth in Norway (quarterly average) generated by NEMO, the macroeconomic model used by the Norges Bank for policy-making. ${ }^{20}$ Finally, $y_{t}$ is the output gap from NEMO (quarterly average). The output gap is constructed by deducing potential growth, as determined by NEMO, from the Norges Bank's mainland GDP growth forecast, as published in the Monetary Policy report. All of the variables on the right-hand side, except the wage growth series, are real-time variables, available at the time of actual policy rate decisions. ${ }^{21}$ This might be particularly important for our purposes, as the published interest rate forecasts added to the rules are also real-time variables.

Finally, a comment on the actual timing of the publication of interest rate forecasts by the Norges Bank is warranted. As mentioned above, the Norges Bank only announces interest rate forecasts three times a year, namely in March, June and October. To obtain quarterly data, we consider forecasts published in June thirdquarter observations, i.e., interest rate forecasts produced in the third quarter. By doing so, the September forecasts are "slided" cross-sections of June forecasts by one quarter. ${ }^{22}$

\subsubsection{Generalized Taylor Rule}

The extended Taylor Rule of Clarida, Galí and Gertler (1999) is used for both countries as an alternative to the country-specific ones. According to the rule, the actual policy rate is partially adjusted to the target rate and the target rate, is defined as:

\footnotetext{
${ }^{19}$ Namely: Sweden, the US, Germany, the UK, Japan, Canada, Poland, Denmark, Czech Republic and Hungary.

${ }^{20}$ In contrast to the data in the US, for instance, the wage growth series seem to be less noisy in the Norwegian data and, as it will be seen in the results section, explains a non-trivial portion of the movement in the key policy rate.

${ }^{21}$ See Orphanides (2001) for a discussion on the importance of using real-time vs. historical data when estimating policy rules.

${ }^{22}$ The 2-quarters-ahead forecast from June becomes the 1-quarter-ahead forecast in September for the (same) average key policy rate in December and so on.
} 


$$
i_{t}^{*}=\gamma^{\pi} E_{t} \pi_{t+1}+\gamma^{y} E_{t} y_{t+1}
$$

where $E_{t} \pi_{t+1}$ and $E_{t} y_{t+1}$ denote expected inflation and output gap, respectively. For New Zealand, we use the previously mentioned 2-year inflation expectations from the RBNZ survey. The expected inflation data for Norway and the expected output gap data for both countries are published in the monetary policy reports of the RBNZ and the Norges Bank.

We use the following specification to test whether $\kappa_{j}=0$ for $j=\{s, l\}$ for both the institution-specific and the generalized Taylor rule of Clarida et al. (1999):

$$
i_{t}=\Omega_{\text {partial }}^{*}\left[\begin{array}{llll}
1 & \varphi & \kappa_{s} & \kappa_{l}
\end{array}\right]\left[\begin{array}{c}
i_{t}^{*} \\
i_{t-1} \\
i_{t-s, t}^{p} \\
i_{t-l, t}^{p}
\end{array}\right]
$$

where

$$
\Omega_{\text {partial }}^{*}=\frac{1}{1+\varphi+\kappa_{s}+\kappa_{l}}
$$

and where $i^{*}$ is the appropriate target rate for an individual central bank, institutionspecific or the one proposed in Clarida et al. (1999).

\subsection{3 "Calvo-Rule"}

Finally, we consider a policy rule with a weight on the expected future interest rate. We denote this a "Calvo-Rule". The term was introduced by Levine, McAdam and Pearlman (2007) to describe a policy that weights a discounted sum of future inflation, while Bache et al. (2011) derive such a policy from the perspective of optimal interest rate smoothing and show that it can be represented as a policy rule with a weight on the expected future interest rate. Note that by adding the interest rate forecasts to the rule, the specification is identical to the most general one from equation (3). The target rate $i_{t}^{*}$ we model as in Clarida et al. (1999), with the expected interest rate $E_{t} i_{t+1}$ approximated by the 1-quarter ahead forecast published by the two central banks. 


\subsection{Estimating the Model}

Without loss of generality, let us consider the reaction function defined in (8) for the target rate according to Clarida et al. (1999). For both central banks, we estimate:

$$
i_{t}=\frac{1}{1+\varphi+\kappa_{s}+\kappa_{l}}\left[\begin{array}{llll}
1 & \varphi & \kappa_{s} & \kappa_{l}
\end{array}\right]\left[\begin{array}{c}
\gamma^{\pi} E_{t} \pi_{t+1}+\gamma^{y} E_{t} y_{t+1} \\
i_{t-1} \\
i_{t-s, t}^{p} \\
i_{t-l, t}^{p}
\end{array}\right]+\varepsilon_{t}^{i}
$$

where $\varepsilon_{t}^{i}$ is modeled as an $\operatorname{AR}(1)$ process in line with Rudebusch (2002):

$$
\varepsilon_{t}^{i}=\lambda \varepsilon_{t-1}^{i}+\zeta_{t}
$$

and $\zeta_{t}$ is assumed to be i.i.d $N\left(0, \sigma_{\zeta}\right)$. Accordingly, we allow for separation between the policy inertia, i.e. the preference for interest rate smoothing, and the persistence of the shock itself. The null hypothesis is that estimated coefficients $\kappa_{s}$ and $\kappa_{l}$ are not significantly different from zero, i.e., the policymakers do not adhere to previously announced interest rate forecasts. The equations (9) (the reaction function) and (10) (autocorrelated error) are estimated by maximizing the appropriate likelihood function. ${ }^{23}$ Our key result refers to the policy rule with the shorthorizon forecast $s=1$ only, i.e. the forecast added to the rule is the 1-quarter-ahead forecast announced one quarter before the policy rate is set. Adding longer-horizon forecasts and estimating policy rules with $s=1$ and $l=\{2,3, \ldots 8\}$ yields identical results as the $s=1$ case, see section 4.3 .

In all of the reaction functions we estimate, the announced forecasts are orthogonal to the lagged policy rate. ${ }^{24}$ We regress the forecasts on the policy rate as follows:

\footnotetext{
${ }^{23} \mathrm{~A}$ standard line-search algorithm is used to estimate the system, where the descent direction is calculated using the Quasi-Newton method.

${ }^{24}$ Additionally, we correct the RBNZ forecasts for the spread between the 90-day Bank Bill rate and the policy rate by subtracting the time varying (quarter average) spread from the forecasts.
} 


$$
i_{t, t+h}^{p}=\beta_{0}+\beta_{1} i_{t-1}+\varepsilon_{t}^{p, h}
$$

and use the residuals from the regression, instead of the original forecast series, in the interest rate rules. In such a way, the forecast variables added to different rules include only information beyond the general level of interest rates. Interestingly, when the original forecast series are included in rules, the lagged policy rate, and not the forecasts, become insignificant due to collinearity. ${ }^{25}$

\section{Results}

Our main results are reported in tables 1 and 2, where we test for adherence to 1-quarter-ahead forecasts announced in the quarter before the actual policy rate is set. We discuss the findings for each country separately, beginning with New Zealand.

\subsection{Estimated Reaction Functions}

\subsubsection{RBNZ}

The first column from the left in table 1 reports the estimated coefficients of the policy rule from the K.I.T.T. model, with inflation expectations and lagged interest rate as the only arguments. The second column reports the estimated coefficients for the same interest rate rule when the forecast of the 1-quarter-ahead Bank Bill rate announced in a previous quarter is added. Similar pairwise exercises are performed for the Clarida et al. (1999) rule in columns 3 and 4 and for the forwardlooking Calvo-type rule in columns 5 and 6. For each coefficient, the t-statistic is reported in brackets. Our main parameter of interest is $\kappa_{s}$, the weight on past forecasts.

\section{TABLE 1 ABOUT HERE}

\footnotetext{
${ }^{25}$ In all the augmented specifications we estimate for the RBNZ, and in the "Calvo" specification we estimate for the Norges Bank, we constrain the coefficient $\varphi$ in front of the lagged policy rate to be equal to its value from the rule without interest rate forecasts. When we exclude the constraint, the algorithm does not converge to a finite solution.
} 
The main insight from table 1 is that for all three specifications, $\kappa_{s}$ is positive and statistically significant. Therefore, the RBNZ seem to have adhered to its own forecasts. Furthermore, adding these forecasts to the reaction functions makes the AR(1) element of the error terms in the KITT and the "Calvo" rules become insignificant. In other words, previously published forecasts seem to explain some of the systematic deviation of the actual policy rate from the "target" rate implied by the conventional simple rule without forecasts. However, this is not the case for all of the estimated reaction functions.

We also see that the 2-years-ahead inflation expectations seem to explain a significant amount of the variation in the actual policy rate. This is reasonable, as the RBNZ is a strict inflation targeter. Yet it is somewhat puzzling that the inflation expectations variable is not statistically significant in all specifications, especially when the interest rate forecast is added to the rule. As a robustness check, we therefore extended the analysis by adding the forecast term to the rule that is orthogonal to both the lagged policy rate and expected inflation. The results did not change, and we therefore do not report the outcome of this exercise. ${ }^{26}$

The in-sample fit of all the rules without the forecast terms is relatively high, so the forecasts are less likely to capture some other (forward-looking) information omitted in the original rules. However, the forecasts do explain a statistically significant portion of the actual policy rate variation. The upper panel of Figure 3 plots the estimated residuals from the Clarida et al. (1999) rule without (red bars) and with (solid blue line) the 1-quarter-ahead forecast in the rule. We see that the interest rate forecasts seem to play an important role in the policymaker's reaction pattern, as the residuals from the augmented rule on average are lower than those of the original rule. ${ }^{27}$

\section{FIGURE 3 ABOUT HERE}

Moreover, augmenting the standard policy rules with the forecast terms identifies some episodes in the actual policy rate setting, where the rate differed from what the original rule suggested. For instance, the RBNZ increased the policy rate two times during the second quarter of 2002, from 5 to $5.5 \%$. The CGG rule suggests the average policy rate for the quarter of $4.91 \%$ as appropriate and the 1-quarter

\footnotetext{
${ }^{26}$ The results are available on request.

${ }^{27}$ The original rule residuals have a mean of -1.6 and standard deviation of 30 basis points, versus the -1 basis point mean and 20 basis point standard deviation of the augmented rule residuals.
} 
ahead forecast for the 90-day Bill rate that the RBNZ published in the previous quarter was 5.41\%. Another example would be March 9, 2006 when the RBNZ decided to leave the OCR unchanged at $7.25 \%$, whereas the policy rule suggests a cut to $7 \%$ and the previously announced 1-quarter ahead forecast for the 90day Bill rate was 7.6\%. On September 16, 2010, the RBNZ's OCR rate was at $3 \%$, while the Taylor rule suggests $2.5 \%$ as appropriate, and the 1-quarter ahead interest rate forecast announced in June of the same year was $3.28 \%$. It took another 3 policy meetings before the policy rate was cut to 2.5\% in March 2011, and the 1-quarter forecast for the 90-day Bank bill rate was lowered to $2.86 \%$.

\subsubsection{Norges Bank}

Table 2 reports the corresponding results for the estimated reaction function of the Norges Bank. Coefficients and t-statistics are calculated using asymptotic standard errors (in brackets).

\section{TABLE 2 ABOUT HERE}

Similar to the case of the RBNZ, the Norges Bank seems to adhere to the 1quarter-ahead interest rate forecast, as $\kappa_{s}$ is estimated to be significant in all specifications. The expected output gap is another important variable in the estimated policy rules, whereas the coefficient of inflation is significantly different from zero only when the Clarida et al. (1999) rule is used. The improvement of the fit due to the inclusion of the interest rate forecasts is again marginal, but helpful in explaining some of the estimated policy shocks from the original rules.

The lower panel of Figure 3 again plots the residuals from the estimated Clarida et al. (1999) rule without the forecasts terms (red bars) and including the 1-quarter-ahead forecasts (blue solid line). ${ }^{28}$ The rule augmented with adherence apparently explains several policy decisions better than the original rule, which indicates that these decisions might have been particularly strongly affected by the previously announced forecasts. For example, the key policy rate in the third quarter of 2008 was $5.75 \%$, whereas the estimated policy rule suggests $5.5 \%$ as the appropriate level (the residual from the original rule is 26.4 basis points) and the 1-quarter ahead forecast for the key policy rate, published in June 2008, was

\footnotetext{
${ }^{28}$ Similar to the RBNZ case, augmenting the original rule reduces the mean of the estimated shocks from -1.3 basis points to 0.2 and the standard deviation from 21 basis points to 12 .
} 
$5.75 \%$. Another example is the second quarter of 2010, when the previously announced 1-quarter-ahead forecast stood at $1.9 \%$ and the policy rate was set to $2 \%$ at the end of the quarter, while the original Clarida et al. (1999) rule suggests $1.75 \%$. As the figure shows, there are other episodes where the forecasts added no additional information to the original rules, yet on average policy seems to have adhered to previously announced short-horizon forecasts.

\subsection{The Preferred Policy Rates}

In this section we approach our empirical question from a slightly different angle. We consider two different proxies for what the interest rate would have been without adherence, referred to as the "preferred" rate, and thereafter evaluate whether adherence is significant after controlling for the preferred rate.

\subsubsection{Using the Estimated Rules}

We "construct" the preferred policy rate series for the two central banks from the estimated interest rate rules without the previously announced forecasts. There are three such estimates for each central bank, namely the fitted policy rate according to the institution-specific rules (the KITT model documentation for the RBNZ and Bernhardsen (2008) for the Norges Bank), the generalized Taylor rule (Clarida et al. (1999)) and the "forward looking" rule (Levine et al. (2007)). Once we obtain the fitted policy rates, we perform the following two regressions:

$$
i_{t}=\widetilde{\Omega} \widetilde{i_{t}}+\widetilde{\kappa_{1}} i_{t-1, t}^{p}+\varepsilon_{t}
$$

and

$$
i_{t}=\widetilde{\Omega} \widetilde{i_{t}}+\widetilde{\kappa_{1}} \varepsilon_{t}^{p, 1}+\varepsilon_{t}
$$

where $\widetilde{i_{t}}$ is the preferred policy rate, $i_{t-1, t}^{p}$ is the 1-quarter-ahead forecast announced in a previous quarter and $\varepsilon_{t}^{p, 1}$ is the residual from the regression (11), i.e., the 1-quarter-ahead forecast orthogonal to the lagged policy rate. We use the 
2-step General Least Squares (GLS) model of Hoffman (1987) to estimate the regression coefficients and therefore account for the so called "generated regressor" problem. Table 3 reports the parameter estimates.

\section{TABLE 3 ABOUT HERE}

The "weight" the RBNZ places on the 1-quarter ahead interest rate forecasts is significantly different from zero in all the estimated equations, independent of whether we use the original time-series of the forecast or that orthogonal to the lagged policy rate (the residual term from the equation (11)). The estimates for the Norges Bank are similar, whereas the forecast series orthogonal to the lagged policy rate is only marginally significant. Overall, the main result holds.

\subsubsection{Using "Nowcasts" as the Preferred Policy Rate}

Interest rate rules provide a simplistic description of monetary policy. Decisions regarding the appropriate policy rate can be systematically influenced by the omitted factors such as financial market conditions, house prices or judgment. All of these factors could in principle be correlated with past interest rate forecasts. In addition to the omitted variable problem, it could also be the case that the 1quarter-ahead forecasts are simply "good" forecasts of the policy rate, which we misinterpret as forecast adherence.

We address these potential issues by using the two central banks' "nowcasts" of the policy rate as the preferred policy stance in a current quarter. ${ }^{29}$ The nowcasts are produced by the core macroeconomic models of the central banks and combined with judgment before being released in the monetary policy reports. ${ }^{30}$ It is therefore likely that these nowcasts capture the factors that have systematically influenced monetary policy in the two countries. Moreover, the information content from past forecasts is embedded in the current information set. If the announced paths are merely forecasts, they should have no predictive power on the policy rate over and above the nowcasts.

\section{TABLE 4 ABOUT HERE}

\footnotetext{
${ }^{29}$ The nowcasts published by the Norges Bank concern the key policy rate, while as previously explained, the RBNZ announces the nowcasts of the 90-day Bank Bill rate. We adjust the latter for the spread between the Bank Bill rate and the policy rate.

${ }^{30}$ See Drew and Karagedikli (2008) and Holmsen et al. (2008).
} 
Table 4 reports the estimated coefficients from equations (12) and (13) where we use the nowcasts as the preferred policy rate $\tilde{i_{t}}$. The key insight remains intact: the two central banks appear constrained by their most recently announced forecasts. When we use the orthogonalized series of forecasts, the result remains the same for the RBNZ and we obtain a marginally significant $\widetilde{\kappa_{1}}$ for the Norges Bank. As the nowcasts contain the most up-to-date information about the current state of the economy and the two central banks' judgments about the appropriate policy, it is unlikely that our main result reflects a superior forecasting ability of past interest rate forecasts.

\subsection{Longer Horizon Forecasts}

The actual policy rate seems to be affected by the interest rate forecast announced in the preceding quarter, but not by the forecasts announced before that. This is clear from tables 5 and 6, which illustrate the results for $s=1$ ( 1 quarter) and $l=2$ (2 quarters ahead), for the RBNZ and the Norges Bank, respectively.

TABLES 5 AND 6 ABOUT HERE

We have also estimated the rules using forecast horizons from 3 to 8 quarters ahead. The mid- and long-range forecast above 1-quarter ahead do not add any information to the estimated rules.

\subsection{Does Our Empirical Strategy “Cry Wolf”?}

We specify policy in terms of simple rules rather than the minimization of an explicit objective function. A natural concern is that our findings falsely indicate a preference for adherence, when in reality no such preference exists. To address this issue, we apply our empirical approach to data that are artificially generated from an environment where the central bank's true preferences are known.

\subsubsection{The Model}

We simulate data from the standard 3-equation New Keynesian model used in Gersbach and Hahn (2011), where the central bank optimally sets policy to min- 
imize a loss function over output and inflation, and potentially is also concerned about deviations from the previously announced 1-period-ahead forecasts of the policy rate. As explained in the Data Section, both the RBNZ and the Norges Bank announce interest rate forecasts conditional on future inflation and output gap forecasts. In principle, these forecasts might also carry a weight. We thus incorporate the costs of deviating from inflation projections, as in Gersbach and Hahn (2011).

The Phillips curve, determined by forward-looking price-setters, reads:

$$
\pi_{t}=\delta E_{t}\left[\pi_{t+1}\right]+\lambda y_{t}+\chi_{t}
$$

where $\chi_{t}$ is an $\operatorname{AR}(1)$ cost-push shock:

$$
\chi_{t}=\rho_{\chi} \chi_{t-1}+\varepsilon_{t}^{\chi}
$$

The dynamic IS curve is given by:

$$
y_{t}=E_{t}\left[y_{t+1}\right]+\sigma\left(i_{t}-E_{t}\left[\pi_{t+1}\right]\right)+\omega_{t}
$$

where $\omega_{t}$ is an $\operatorname{AR}(1)$ demand shock:

$$
\omega_{t}=\rho_{\omega} \omega_{t-1}+\varepsilon_{t}^{\omega}
$$

In every period $t$, the central bank sets the current interest rate $i_{t}$, the 1-quarterahead inflation forecast $\pi_{t+1, t}^{P}$, and the 1-quarter-ahead interest rate forecast $i_{t+1, t}^{P}$ to minimize the following loss function:

$$
\mathscr{L}_{t}=\frac{1}{2} E_{t} \sum_{k=0}^{\infty} \delta^{j}\left(\pi_{t+k}^{2}+a y_{t+k}^{2}+b\left(\pi_{t+k}-\pi_{t-1+k, t+k}^{P}\right)^{2}+c\left(i_{t+k}-i_{t-1+k, t+k}^{P}\right)^{2}\right)
$$

The parameters $a, b$ and $c$ describe the central bank's preference for stabilizing output and minimizing the costs of deviating from previous inflation- and interest 
rate forecasts, respectively. The three weights are all normalized by the weight on inflation. Note that the central bank internalizes how its choice of interest rate forecast affects future policy and thereby future output and inflation. In this sense, the interest rate path becomes a "commitment device", allowing the central bank to affect private expectations, because reneging on these "promises" is costly.

\subsubsection{Model Simulation and Estimated Policy Rule}

As the central bank re-optimizes in every period, by setting the current policy rate and announcing the optimal policy rate in the next period, the policymaker's reaction function can not be expressed in a closed form (in terms of $a, b$ and $c$ ). To relate our empirical approach to the optimal policy in this specific environment, we first simulate the model, assuming different values of deviation costs $b$ and $c$, and then estimate the following non-inertial Taylor rule on simulated data samples:

$$
i_{t}^{s i m}=\gamma^{\pi} \pi_{t}^{s i m}+\gamma^{y} y_{t}^{s i m}+\rho_{1} i_{t-1, t}^{P, s i m}+\vartheta_{t}
$$

where $\vartheta_{t}$ is an $\mathrm{AR}(1)$ process. The higher we set the coefficient $c$ in the loss function, the higher the estimate of coefficient $\rho_{1}$ in the rule should be. The model is solved for optimal policy under discretion using the algorithm of Söderlind (1999). We generate 3,000 samples of data, where each sample contains 60 observations. We then estimate the equation (15) on each sample and report the means of estimated parameters in table 7 , together with t-statistics (in brackets) calculated using the standard deviation of those estimates. The upper panel provides the model parametrization that we employ, which consists of the same values as in Clarida et al. (2000).

\section{TABLE 7 ABOUT HERE}

The lower panel illustrates the key takeaway from the exercise: our estimated simple policy rules do not commit false positive errors. The coefficient on the interest rate forecast $\rho_{1}$ is only significantly different from zero if the "true" reluctance to deviate from previous forecasts is relatively strong. In our exercise, the empirical strategy implies adherence when $c$ is above 0.2 , i.e. when the weight on deviations from the announced interest rate forecasts is equal to one-fifth of the weight on 
inflation. In the other two cases, when $c=10^{-7}$ i.e. practically zero, ${ }^{31}$ and $c=.1$, previous interest rate forecasts appear unimportant in the reduced-form reaction function. ${ }^{32}$

\section{TABLE 8 ABOUT HERE}

Most important, this result is independent of whether the policy rule we estimate on the simulated data is misspecified. Excluding the output gap term from equation (15) will still not lead us to commit false positive errors when measuring forecast adherence with the interest rate rules, see table 8 .

\subsection{Policy Rate Surprises}

Our interpretation of the empirical findings is that the two central banks find it costly to deviate from their own forecasts. Such costs introduce an additional adjustment term in the banks' reaction functions, and constrain policymaking over and above the desire to smooth the policy rate itself. In this section we discuss whether our results might be explained by a completely different assumption, namely that the central banks aim to minimize surprises in the policy rate, as suggested by Svensson (2003). ${ }^{33}$

Suppose that the central bank's optimization problem can be described by the following loss function:

$$
\mathscr{L}_{t}=\frac{1}{2} E_{t} \sum_{k=0}^{\infty} \delta^{k}\left[\begin{array}{c}
\left(i_{t+k}-i_{t+k}^{*}\right)^{2}+\varphi\left(i_{t+k}-i_{t+k-1}\right)^{2} \\
\kappa_{1}^{E}\left(i_{t+k}-E_{t+k-1} i_{t+k}\right)^{2}
\end{array}\right],
$$

where the first two terms describe, as previously explained, the central bank's objectives to set the actual policy rate according to the state of the economy, in a gradual fashion, respectively. The parameter $\kappa_{1}^{E}$ captures the bank's preferences for minimizing the difference between the current policy rate $i_{t}$ and the expected

\footnotetext{
${ }^{31}$ With $c=0$, the interest rate deviation term from the loss function vanishes and the interest rate forecasts are not determined.

${ }^{32}$ The variation in the values of the estimated inflation coefficient $\gamma^{\pi}$ is in line with Cochrane (2007), who argues that the Taylor rule parameter $\gamma^{\pi}$ cannot be identified by regressing the policy rate on inflation.

${ }^{33}$ See also Rudebusch (2006).
} 
policy rate one period before the decision, $E_{t-1} i_{t}$. If the future short-rate expectations of the central bank and the public are perfectly aligned, and if we further assume that the public and not the central bank "dictates" those expectations, our empirical strategy captures the policymaker's effort to reduce surprise movements in the policy rate and not to stick to its promises.

Let us consider the two assumptions individually. As we have shown, our main result concerns the shortest-horizon forecasts announced a quarter before the actual policy rate is set. Over the course of any three-month period, we might indeed assume that the uncertainty around a policymaker's decisions is relatively low (with respect to medium- or long term outlook) and thus the expectations of the central bank and the markets are broadly aligned. The better the proxy for market expectations one has, the closer the results of estimating the reaction function of the policymaker in (16) are going to be to our results. Yet, the central banks we consider publish their own interest rate forecasts, and thus a positive and significant $\kappa_{1}^{E}$ coefficient de facto means that the two central banks adhere to their own forecasts, irrespective of whether the underlying motive is to avoid the loss of reputation or minimize surprises in the policy rate. The two explanations are complementary and empirically indistinguishable.

Only if the second assumption holds, does our explanation that the central banks adhere to their own short-horizon forecasts fail. As the market expectations are those that guide the central banks' short-rate expectations, the estimates of $\kappa_{s}$ that we report in tables 1 and 2 measure the policymaker's effort to reduce policy surprises. Nevertheless, the assumption is quite strong. It means that the RBNZ and the Norges Bank publish their own forecasts by relabeling market expectations. There might be some anecdotal evidence that the central banks that publish interest rate forecasts occasionally adjust those forecasts to appear similar to the observed forward rate curve on the day prior to the announcement, but it is unlikely that this relabeling is done in a systematic way, without discussing it openly in monetary policy reports.

Finally, if our results are entirely driven by a preference for conforming to market expectations, this preference should also have influenced policy before the practice of publishing paths was introduced. This is testable, and we turn to such a test in the next section. 


\subsection{Placebo Test}

We ask whether the Norges Bank "adhered" to market expectations and run our regressions on the Norges Bank data before it began announcing interest rate forecasts in November 2005. ${ }^{34}$ We approximate market expectations with the 3month forward rate. As explained in the previous section, this is not simply a "placebo test" of our strategy, but it also indicates whether our main findings are driven by preferences for avoiding policy surprises. If we find that the Norges Bank had no such incentives prior to 2005, it is reasonable to believe that no such preferences existed after 2005 either. To appreciate the potential importance of aversion to policy surprises, we consider a central bank that might have been concerned in the past about disappointing market expectations, namely the Bank of England (BoE). ${ }^{35}$

We solve the optimization problem in equation (16) with respect to $i_{t}$, and estimate the following reaction function for the BoE from 2001 to 2009 and for the Norges Bank from 1999 to 2004:

$$
i_{t}=\Omega_{E}^{*}\left[\begin{array}{lll}
1 & \varphi_{E} & \kappa_{1}^{E}
\end{array}\right]\left[\begin{array}{c}
\gamma^{\pi} E_{t} \pi_{t+1}+\gamma^{y} E_{t} y_{t+1} \\
i_{t-1} \\
E_{t-1} i_{t}
\end{array}\right]+\varepsilon_{t}^{E}
$$

where

$$
\Omega_{E}^{*}=\frac{1}{1+\varphi_{E}+\kappa_{1}^{E}}
$$

and where the target rate is defined as in Clarida et al. (1999), $E_{t-1} i_{t}$ is the 3month forward rate orthogonal to the lagged policy rate and $\varepsilon_{t}^{E}$ is again allowed to have an AR(1) component. For the 1-period-ahead inflation and output gap expectations in the BoE case, we use the forecasts published in the Inflation Report. ${ }^{36}$

\footnotetext{
${ }^{34}$ Since 1999, monetary policy in Norway has been conducted in pursuit of low and stable inflation and its operational procedures have remained broadly unchanged. However, the monetary policy implemented by the RBNZ was substantially different before the beginning of the sample used, see for example the Reserve Bank Bulletin from March 1999.

${ }^{35}$ See Appendix A for a brief description of policymaking at the BoE and some anecdotal evidence of preferences towards reducing surprises in the policy rate.

${ }^{36}$ The BoE publishes forecasts for GDP growth and not the output gap, as the RBNZ and the Norges Bank do. We use the demeaned GDP growth forecast for the $E_{t} y_{t+1}$ variable in the rule.
} 
Table 9 reports the results.

\section{TABLE 9 ABOUT HERE}

Our empirical strategy passes the placebo test for the Norges Bank: The 3-month forward rate has no explanatory power for the policy rate in Norway. This adds credibility to the interpretation of our main results. Moreover, it implies that the Norges Bank did not "adhere" to the market forecasts and apparently did not have a preference for minimizing surprises in the policy rate over and above what the interest rate smoothing might imply. Moreover, we also observe that our estimation finds adherence to market expectations where we a priori would expect that such preferences exist: We report a positive yet marginally significant $\kappa_{1}$ coefficient in the policy rule for the BoE, which is known to emphasize market expectations when setting its interest rate.

\section{Conclusion}

The practice of explicitly announcing future monetary policy intentions has been widely recommended in the theoretical literature and increasingly implemented by several central banks, including the Federal Reserve. Our findings indicate that the actual policy decisions of the two central banks with the longest history of publishing interest rate forecasts might have been constrained by those forecasts. Once the future interest rate paths are announced, the two central banks appear reluctant to deviate from their short horizon projections.

Normatively, the question of whether forecast adherence is beneficial remains an open question. Adherence might indicate that policymakers use published interest rate paths as a commitment device to increase policy effectiveness. However, reluctance to deviate from past forecasts might prevent policymakers from reacting sufficiently strongly to unexpected shocks. Addressing these arguments requires further theoretical and empirical work.

\section{References}

Alstadheim, Ragna, Ida Wolden Bache, Amund Holmsen, Junior Maih, and Øistein Røisland (2010) “Monetary policy analysis in practice," Norges Bank Mone- 
tary Policy Staff Memo, October.

Andersson, Magnus and Boris Hofmann (2009) "Gauging the effectiveness of quantitative forward guidance: evidence from three inflation targeters," Working Paper Series 1098, European Central Bank.

Bache, Ida Wolden, Øistein Røisland, and Kjersti Næss Torstensen (2011) "Interest Rate Smoothing and "Calvo-Type" Interest Rate Rules: A Comment on Levine, McAdam, and Pearlman (2007)," International Journal of Central Banking, Vol. 7, No. 3, pp. 79-90, September.

Benes, Jaromir, Andrew Binning, Martin Fukac, Kirdan Lees, and Troy Matheson (2009) "K.I.T.T.: Kiwi Inflation Targeting Technology," Reserve Bank of New Zealand 2009, June.

Bernhardsen, Tom (2008) "The relationship between the key policy rate and macroeconomic variables: A simple cross-check for Norway," Norges Bank Staff Memo, June.

Brubakk, Leif, Tore Anders Husebø, Junior Maih, Kjetil Olsen, and Ø stnor Magne (2006) "Finding NEMO: Documentation of the Norwegian economy model," Norges Bank Staff Memo, June.

Campbell, Jeffrey R., Charles L. Evans, Jonas D.M. Fisher, and Alejandro Justiniano (2012) "Macroeconomic Effects of FOMC Forward Guidance," Conference Draft, March.

Clarida, Richard, Jordi Galí, and Mark Gertler (1999) "The Science of Monetary Policy: A New Keynesian Perspective," Journal of Economic Literature, Vol. 37, No. 4, pp. 1661-1707, December.

(2000) "Monetary Policy Rules And Macroeconomic Stability: Evidence And Some Theory," The Quarterly Journal of Economics, Vol. 115, No. 1, pp. 147-180, February.

Cochrane, John H. (2007) "Determinacy and Identification with Taylor Rules," NBER Working Papers 13410, National Bureau of Economic Research, Inc.

Drew, Aaron and Özer Karagedikli (2008) "Some benefits of monetary policy transparency in New Zealand," Reserve Bank of New Zealand Discussion Paper Series DP2008/01, Reserve Bank of New Zealand. 
Eggertsson, Gauti B. and Michael Woodford (2004) "Policy Options in a Liquidity Trap,” American Economic Review, Vol. 94, No. 2, pp. 76-79, May.

Gersbach, Hans and Volker Hahn (2011) "Monetary Policy Inclinations," Journal of Money, Credit and Banking, Vol. 43, No. 8, pp. 1707-1717, December.

Goodhart, Charles (2009) "The Interest Rate Conditioning Assumption," International Journal of Central Banking, Vol. 5, No. 2, pp. 85-108, June.

Gosselin, Pierre, Aileen Lotz, and Charles Wyplosz (2008) "The Expected Interest Rate Path: Alignment of Expectations vs. Creative Opacity," International Journal of Central Banking, Vol. 4, No. 3, pp. 145-185, September.

Hoffman, Dennis L. (1987) "Two-Step Generalized Least Squares Estimators in Multi-Equation Generated Regressor Models," The Review of Economics and Statistics, Vol. 69, No. 2, pp. pp. 336-346.

Holmsen, Amund, Jan F. Qvigstad, Øistein Røisland, and Kristin SolbergJohansen (2008) "Communicating monetary policy intentions: The case of Norges Bank."

Kohn, Donald L. (2008) "Recent and prospective developments in monetary policy transparency and communications: a global perspective: a speech at the National Association for Business Economics Session, Allied Social Science,” Speech.

Levine, Paul, Peter McAdam, and Joseph Pearlman (2007) "Inflation-ForecastBased Rules and Indeterminacy: A Puzzle and a Resolution," International Journal of Central Banking, Vol. 3, No. 4, pp. 77-110, December.

Mishkin, Frederic S (2004) “Can Central Bank Transparency Go Too Far?", Vol. The Future of Inflation Targeting, July.

Morris, Stephen and Hyun Song Shin (2002) "The Social Value of Public Information," American Economic Review, Vol. 92, pp. 1521-1534.

Orphanides, Athanasios (2001) "Monetary Policy Rules Based on Real-Time Data," American Economic Review, Vol. 91, No. 4, pp. 964-985, September.

Ranchhod, Satish (2002) "Comparison of interest rate forecast errors: Reserve Bank, NZIER and the National Bank of New Zealand," Working Paper. 
Rudebusch, Glenn D. (2002) "Term structure evidence on interest rate smoothing and monetary policy inertia," Journal of Monetary Economics, Vol. 49, No. 6, pp. 1161-1187, September.

(2006) “Monetary Policy Inertia: Fact or Fiction?” International Journal of Central Banking, Vol. 2, No. 4, December.

Rudebusch, Glenn D. and John C. Williams (2008) "Revealing the Secrets of the Temple: The Value of Publishing Central Bank Interest Rate Projections," in Asset Prices and Monetary Policy: National Bureau of Economic Research, Inc, pp. 247-289.

Söderlind, Paul (1999) "Solution and estimation of RE macromodels with optimal policy," European Economic Review, Vol. 43, No. 4-6, pp. 813-823, April.

Svensson, Lars E. O. (2003) "What Is Wrong with Taylor Rules? Using Judgment in Monetary Policy through Targeting Rules," Journal of Economic Literature, Vol. 41, No. 2, pp. 426-477, June.

(2006) "Social Value of Public Information: Morris and Shin (2002) is Actually Pro Transparency, Not Con,” American Economic Review, Vol. 96, pp. $448-451$.

(2009) “Transparency under Flexible Inflation Targeting: Experiences and Challenges," CEPR Discussion Papers 7213, C.E.P.R. Discussion Papers.

Walsh, Carl E. (2008) "Announcements and the role of policy guidance," Review, No. Jul, pp. 421-442.

Woodford, Michael (2005) "Central-bank communication and policy effectiveness," Discussion Papers 0506-07, Columbia University, Department of Economics.

(2008) "Remarks prepared for the NABE session on "Recent and Prospective Developments in Monetary Policy Transparency and Communications"," working paper, ASSA Meeting, New Orleans.

(2012) "Methods of Policy Accommodation at the Interest-Rate Lower Bound," working paper, Jackson Hole Symposium. 


\section{Appendix A}

Starting from November 2004, the Bank of England (BoE) uses forward rates implied by market yields to condition its key macroeconomic projections of future inflation and GDP growth. The forward rate curve extracted from government bonds (GLC - Government Liability Curve) and the macroeconomic projections are published regularly in the Bank's Inflation Report every February, May, August and November. Such policymaking is well described by the statement of the BoE's Chief Economist, Spencer Dale: “[...] the Committee's preferred approach is to describe its assessment of the outlook for output and inflation, and allow the public and markets to make their own assessment of the likely future path of interest rates." 37

Even before 2004, the BoE dedicated particular attention to the forward rate curve in its Inflation Report, but the conditioning assumption for inflation and GDP forecasts was "no change" in the Bank Rate. ${ }^{38}$ The BoE has regularly commented on the market expectations implicit in the forward curve since the May 2001 Inflation Report, and we therefore use this starting date to estimate the policy rule specified in (17), for which results were reported in Table 9.

Interestingly, the BoE sometimes made comments on the published forward rate curve, which might indicate that these forward rates could matter for the actual policy decisions. Two examples are the following:

" On 6 November, the Monetary Policy Committee increased the repo rate by 0.25 percentage points to $3.75 \%$; in the previous three months official interest rates had not been changed. On 5 November, the general collateral (GC) repo/gilt forward curve suggested that market participants expected interest rates to rise in 2004 and 2005."39

"The Monetary Policy Committee (MPC) has left official interest rates unchanged during the past three months. [...] The forward curve indicates that in the run up to the MPC's meeting on 8-9 February, market participants expected official interest rates to remain broadly unchanged over the next few years. " 40

\footnotetext{
${ }^{37}$ See Andersson and Hofmann (2009).

${ }^{38}$ See Goodhart (2009).

${ }^{39}$ See the BoE Inflation Report from November 2003.

${ }^{40}$ See the BoE Inflation Report from February 2006.
} 


\section{Figures and Tables}

Figure 1: How do Interest Rate Forecasts get Published? The figure reports examples of published interest rate forecasts in the Monetary Policy Statement of the Reserve Bank of New Zealand (upper panel) and in the Monetary Policy Report of the Norges Bank (lower panel).

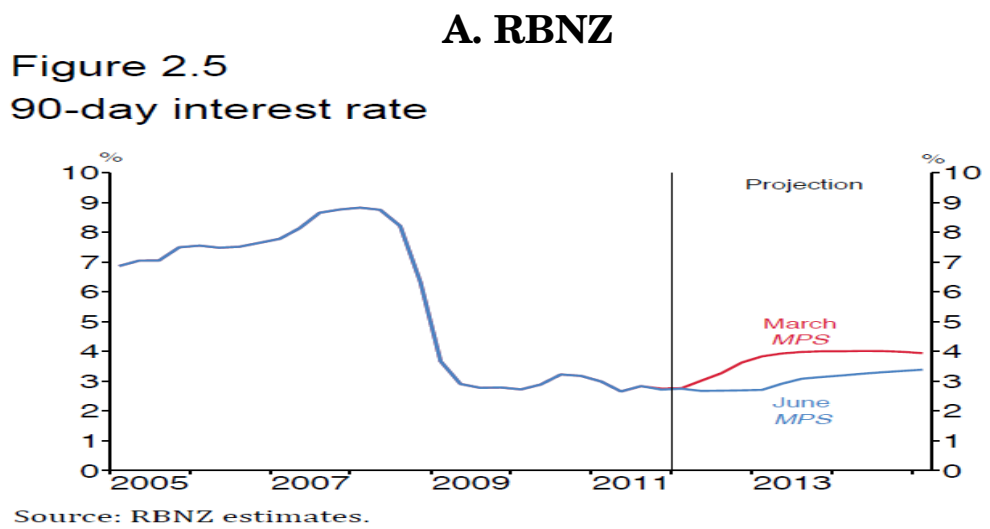

\section{B. Norges Bank}

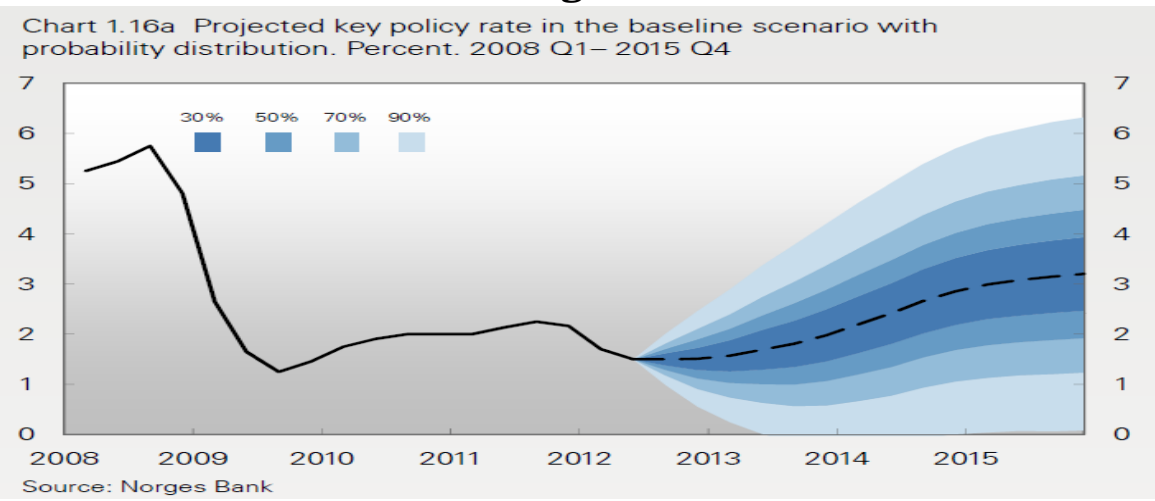


Figure 2: Time-Series of Interest Rate Forecasts. The figure plots monthly series of realized interest rates (dashed black lines) in New Zealand (upper panel) and Norway (lower panel) together with previously announced 1-quarter (solid blue), the 2-quarters (solid green) and 3-quarters (solid red) ahead forecasts for that period.

\section{A. RBNZ}

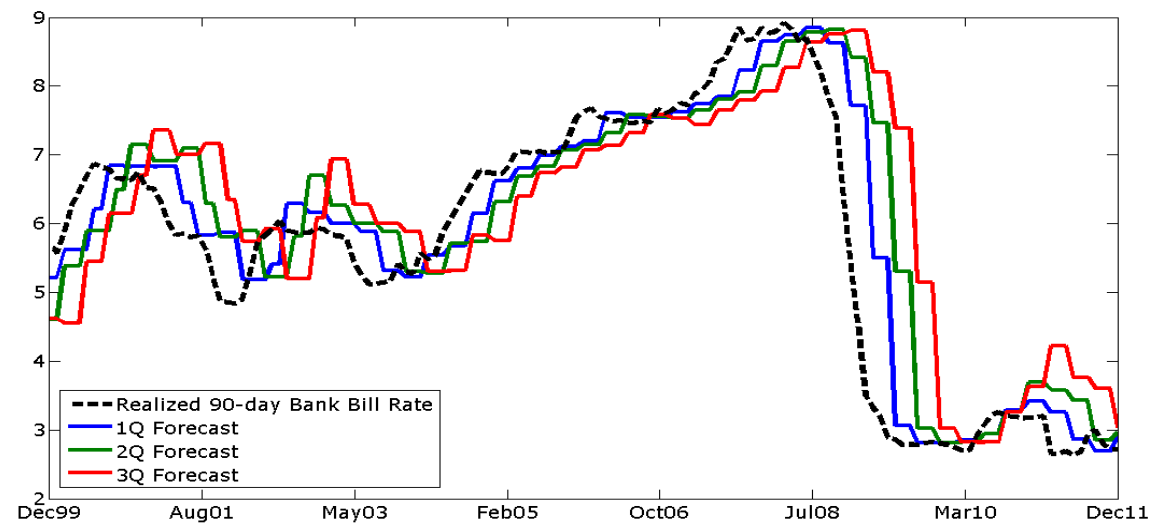

\section{B. Norges Bank}

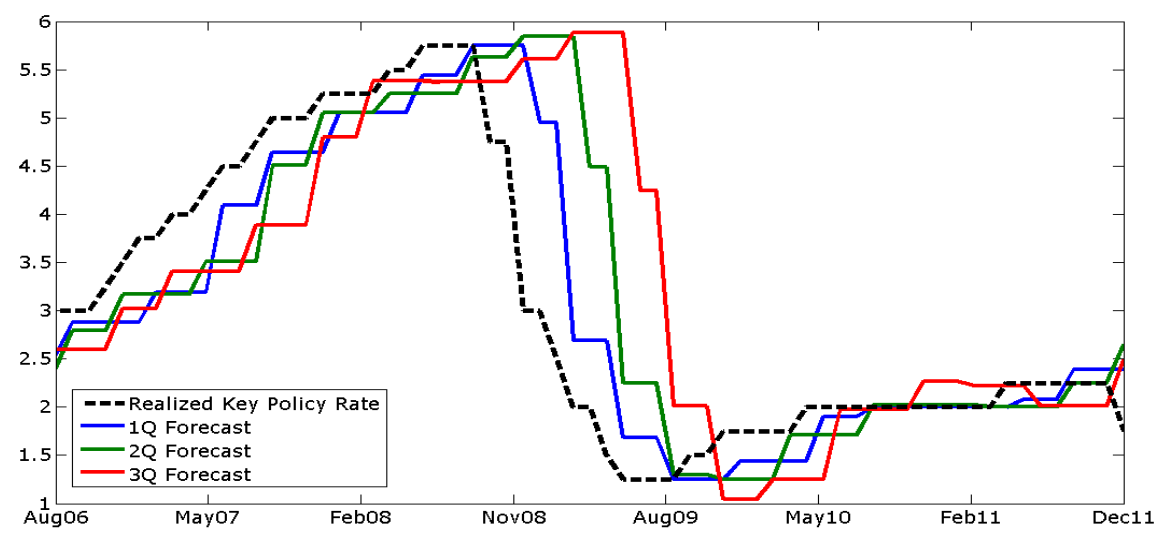


Figure 3: Estimated Policy Shocks. The figure plots residuals from the estimated Clarida et al. (1999) rule from the equation (8) without the 1-quarter-ahead interest rate forecast (red bars), together with residuals from the same rule that includes the previously announced forecast $i_{t-1, t}^{P}$ (solid blue line), estimated for the RBNZ (upper panel) and the Norges Bank (lower panel).

\section{A. RBNZ}

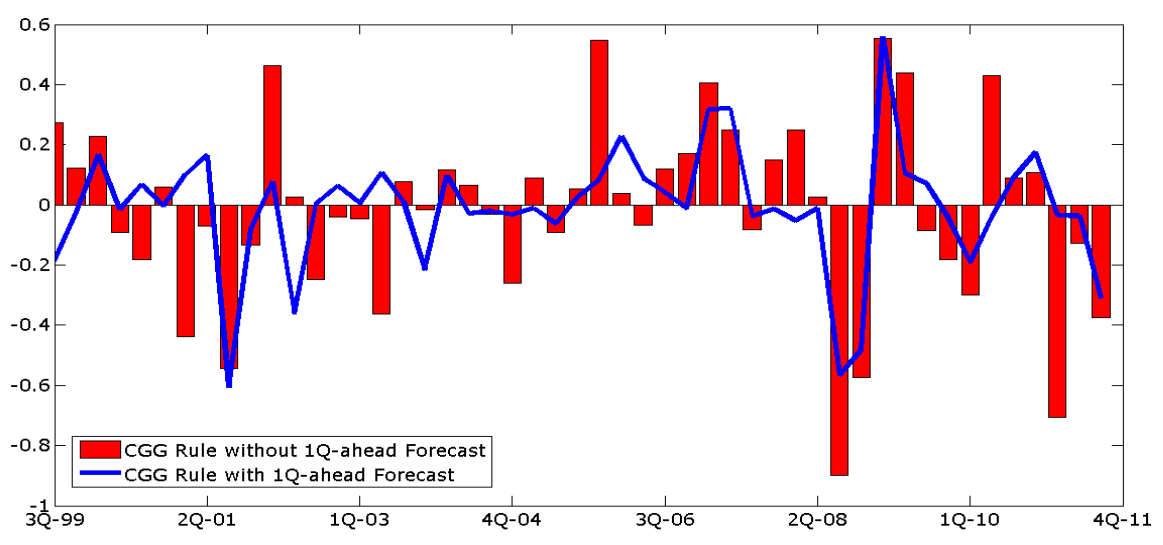

\section{B. Norges Bank}

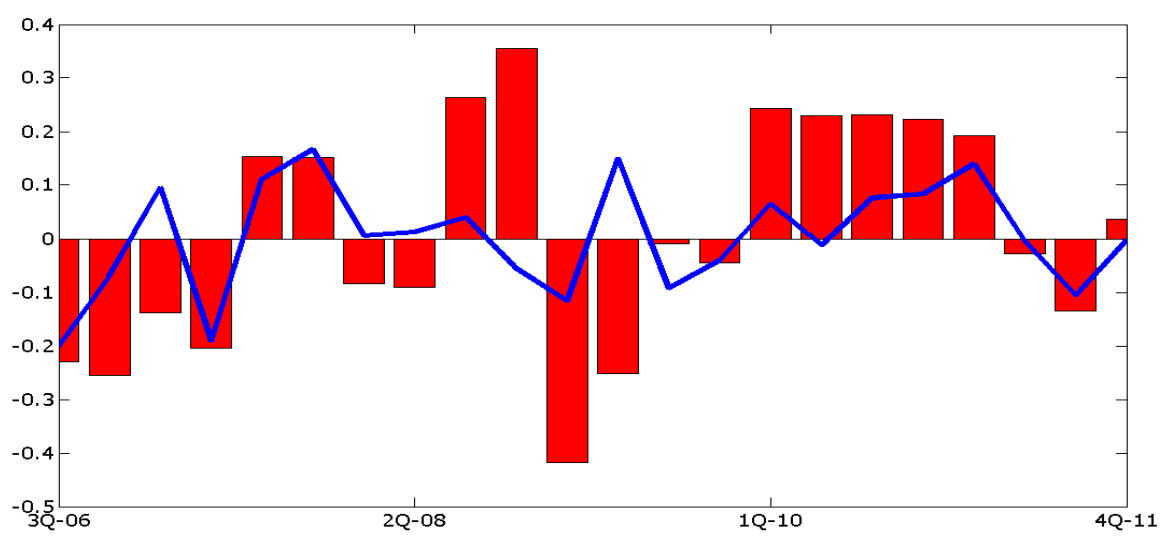


Table 1: Policy Rules for the RBNZ from 1999 - 2011 (1Q Forecasts). Table reports the estimated parameters of the rule from the RBNZ documentation (column KITT), the rule by Clarida et al. (1999) (column CGG) and the Calvo-type rule by Levine et al. (2007) (column Calvo). All specifications are estimated without and with the 3-month-ahead interest rate forecast. Reported t-statistics (in brackets) are calculated using asymptotic standard errors. The remaining rows report F-statistic (F-stat), Durbin-Watson statistic (DW) and adjusted R-squared, and the number of observations is 51 .

\begin{tabular}{ccccccc}
\hline \hline & \multicolumn{2}{c}{ KITT } & \multicolumn{2}{c}{ CGG } & \multicolumn{2}{c}{ Calvo } \\
& - & $s=1$ & - & $s=1$ & - & $s=1$ \\
\hline$\gamma^{\pi}$ & 3.350 & 3.983 & 3.754 & 4.986 & 3.202 & 2.269 \\
& $(8.547)$ & $(1.900)$ & $(11.93)$ & $(1.523)$ & $(23.79)$ & $(3.328)$ \\
$\gamma^{y}$ & & & 1.619 & 1.204 & 0.800 & 0.365 \\
& & & $(8.914)$ & $(0.602)$ & $(17.40)$ & $(1.263)$ \\
$\varphi$ & 2.256 & 2.256 & 5.084 & 5.084 & 2.140 & 1.907 \\
& $(7.290)$ & $(1.069)$ & $(20.99)$ & $(1.177)$ & $(15.25)$ & $(1.693)$ \\
$\delta$ & & & & & 0.467 & 0.524 \\
& & & & & $(3.943)$ & $(0.380)$ \\
$\kappa_{s}$ & & $\mathbf{1 . 5 5 2}$ & & $\mathbf{2 . 5 1 3}$ & & $\mathbf{1 . 1 4 5}$ \\
& & $(2.956)$ & & $(1.738)$ & & $(2.613)$ \\
$\lambda$ & 0.895 & 0.982 & 0.607 & 0.939 & 0.970 & 0.995 \\
& $(6.095)$ & $(2.181)$ & $(5.966)$ & $(1.808)$ & $(23.758)$ & $(3.605)$ \\
F-stat & 3.156 & 1.219 & 19.28 & 4.39 & 13.847 & 18.96 \\
F-stat (CV) & 4.218 & 3.747 & 3.747 & 3.444 & 3.444 & 3.232 \\
DW Statistic & 1.518 & 1.739 & 1.634 & 1.995 & 1.443 & 1.554 \\
Adjusted $R^{2}$ & 0.997 & 0.995 & 0.999 & 0.997 & 0.999 & 0.999 \\
\hline \hline
\end{tabular}


Table 2: Policy Rules for the Norges Bank from 2005 - 2011 (1Q Forecasts). Table reports the estimated parameters from the policy rule in Bernhardsen (2008) (column B), the rule by Clarida et al. (1999) (column CGG) and the Calvo-type rule by Levine et al. (2007) (column Calvo). All specifications are estimated without and with the 3-month-ahead interest rate forecast. Reported t-statistics (in brackets) are calculated using asymptotic standard errors. The remaining rows report F-statistic (F-stat), Durbin-Watson statistic (DW) and adjusted R-squared, and the number of observations is 25 .

\begin{tabular}{ccccccc}
\hline \hline & \multicolumn{2}{c}{ B } & \multicolumn{2}{c}{ CGG } & \multicolumn{2}{c}{ Calvo } \\
& - & $s=1$ & - & $s=1$ & - & $s=1$ \\
\hline$\gamma^{\pi}$ & 0.242 & 0.615 & 0.831 & 1.595 & 1.093 & 1.438 \\
& $(0.804)$ & $(1.305)$ & $(6.416)$ & $(2.250)$ & $(3.699)$ & $(3.192)$ \\
$\gamma^{i n t}$ & 0.832 & 0.121 & & & & \\
& $(2.137)$ & $(0.565)$ & & & & \\
$\gamma^{w}$ & -0.049 & 1.272 & & & & \\
& $-(0.087)$ & $(3.948)$ & & & & \\
$\gamma^{y}$ & 0.468 & 0.524 & 0.961 & 1.309 & 1.264 & 1.128 \\
& $(1.270)$ & $(3.053)$ & $(4.043)$ & $(4.298)$ & $(1.894)$ & $(6.504)$ \\
$\varphi$ & 0.351 & 0.796 & 0.627 & 1.303 & 0.824 & 0.824 \\
& $(0.686)$ & $(1.387)$ & $(5.976)$ & $(1.613)$ & $(1.506)$ & $(2.571)$ \\
$\delta$ & & & & & 0.382 & 0.006 \\
& & & & & $(1.195)$ & $(0.041)$ \\
$\kappa_{s}$ & & $\mathbf{0 . 9 1 5}$ & & $\mathbf{0 . 7 9 9}$ & & $\mathbf{0 . 5 1 8}$ \\
& & $(3.267)$ & & $(1.898)$ & & $(2.075)$ \\
$\lambda$ & 0.923 & 0.240 & 0.367 & 0.086 & 0.367 & 0.138 \\
& $(3.083)$ & $(0.237)$ & $(1.821)$ & $(0.089)$ & $(0.586)$ & $(0.152)$ \\
F-stat & 7.68 & 114.96 & 45.70 & 95.17 & 33.96 & 70.80 \\
F-stat (CV) & 4.015 & 3.927 & 4.431 & 4.171 & 4.171 & 4.015 \\
DW Statistic & 1.204 & 1.960 & 1.845 & 1.964 & 1.845 & 1.976 \\
Adjusted $R^{2}$ & 0.989 & 0.999 & 0.999 & 1.000 & 0.998 & 0.999 \\
\hline \hline
\end{tabular}


Table 3: Fitted Policy Rules as the Preferred Policy Rate. Table reports the estimated parameters from the equation (12) (upper panel) and (13) (lower panel) where the preferred policy rate $\widetilde{i_{t}}$ is estimated using the previously mentioned policy rules for the two central banks. The coefficients are calculated using the 2-step GLS estimator of Hoffman (1987). Reported t-statistics (in brackets) are calculated using Newey-West standard errors. The remaining rows report DurbinWatson statistic (DW) and adjusted R-squared.

\begin{tabular}{cccccccc}
\hline \hline & & & & $i_{t, t+1}^{p}$ & \multicolumn{3}{c}{ Norges Bank } \\
\hline & & RBNZ & & B & CGG & Calvo \\
\hline$\widetilde{\Omega}$ & -0.312 & 0.488 & 0.974 & 0.130 & 0.522 & 0.623 \\
& $-(2.416)$ & $-(1.507)$ & $-(0.272)$ & $-(8.554)$ & $-(3.523)$ & $-(4.352)$ \\
$\widetilde{\kappa_{1}}$ & $\mathbf{1 . 2 3 0}$ & $\mathbf{0 . 5 5 7}$ & $\mathbf{0 . 1 8 7}$ & $\mathbf{0 . 8 3 4}$ & $\mathbf{0 . 4 5 8}$ & $\mathbf{0 . 3 7 7}$ \\
& $(27.46)$ & $(11.21)$ & $(4.652)$ & $(6.265)$ & $\mathbf{( 5 . 6 1 5 )}$ & $(5.537)$ \\
DW Statistic & 0.576 & 0.849 & 1.337 & & 1.309 & 1.300 & 1.551 \\
Adjusted $R^{2}$ & 0.916 & 0.957 & 0.996 & 0.966 & 0.975 & 0.989 \\
& & & & $\varepsilon_{t}^{p, 1}$ & & & \\
& & RBNZ & & & & Norges Bank \\
\hline$\widetilde{\Omega}$ & 1.253 & 0.992 & 0.981 & & 0.748 & 0.937 & 1.003 \\
& $(0.433)$ & $-(0.025)$ & $-(0.185)$ & $-(3.039)$ & $-(0.525)$ & $(0.034)$ \\
$\widetilde{\kappa_{1}}$ & $\mathbf{0 . 4 6 1}$ & $\mathbf{0 . 2 5 9}$ & $\mathbf{0 . 0 7 0}$ & 0.138 & $\mathbf{0 . 1 2 8}$ & 0.028 \\
& $(9.264)$ & $(4.770)$ & $(2.596)$ & $(1.046)$ & $(1.645)$ & $(0.991)$ \\
DW Statistic & 0.576 & 0.849 & 1.507 & 1.309 & 1.300 & 1.711 \\
Adjusted $R^{2}$ & 0.916 & 0.957 & 0.994 & 0.966 & 0.975 & 0.989 \\
\hline \hline
\end{tabular}


Table 4: Central banks' Nowcasts as the Preferred Policy rate. Table reports the estimated parameters from the equation (12) (the columns $i_{t, t+1}^{p}$ ) and the equation (13) (the columns $\varepsilon_{t}^{p, 1}$ ). Reported t-statistics (in brackets) are calculated using Newey-West standard errors. The statistics tell us whether the coefficients $\widetilde{\Omega}$ and $\widetilde{\kappa_{1}}$ are statistically different from 1 and 0 , respectively. The remaining rows report F-statistic (F-stat), Durbin-Watson statistic (DW), adjusted R-squared and the number of observations (N.Obs.).

\begin{tabular}{ccccc}
\hline \hline & \multicolumn{2}{c}{ RBNZ } & \multicolumn{2}{c}{ Norges Bank } \\
& $i_{t, t+1}^{p}$ & $\varepsilon_{t}^{p, 1}$ & $i_{t, t+1}^{p}$ & $\varepsilon_{t}^{p, 1}$ \\
\hline$\widetilde{\Omega}$ & 1.065 & 1.001 & 0.875 & 1.010 \\
& $(2.545)$ & $(0.404)$ & $-(1.667)$ & $(2.301)$ \\
$\widetilde{\kappa_{1}}$ & $\mathbf{- 0 . 0 6 3}$ & $\mathbf{0 . 1 0 8}$ & $\mathbf{0 . 1 3 3}$ & 0.018 \\
& $-(2.594)$ & $(2.264)$ & $(1.681)$ & $(1.601)$ \\
DW Statistic & 1.548 & 1.715 & 1.723 & 2.207 \\
Adjusted $R^{2}$ & 0.998 & 0.998 & 0.994 & 0.993 \\
N.Obs. & 55 & 55 & 24 & 24 \\
\hline \hline
\end{tabular}


Table 5: Policy Rules for the RBNZ from 1999 - 2011 (1Q \& 2 Q Forecasts). Table reports the estimated parameters of the rule from the RBNZ documentation (column KITT), the rule by Clarida et al. (1999) (column CGG) and the Calvotype rule by Levine et al. (2007) (column Calvo). All specifications are estimated without and with interest rate forecasts, whereas the short-horizon forecast is $s=$ 1 (3 months) and the long-range forecast is $l=2$ (6 months). Reported t-statistics (in brackets) are calculated using asymptotic standard errors. The remaining rows report F-statistic (F-stat), Durbin-Watson statistic (DW) and adjusted R-squared, and the number of observations is 50 .

\begin{tabular}{cccc}
\hline \hline & KITT & CGG & Calvo \\
& $s=1, l=2$ & $s=1, l=2$ & $s=1, l=2$ \\
\hline$\gamma^{\pi}$ & 3.764 & 4.003 & 1.940 \\
& $(3.867)$ & $(4.211)$ & $(2.906)$ \\
$\gamma^{y}$ & & 1.307 & 0.270 \\
& & $(2.519)$ & $(0.711)$ \\
$\varphi$ & 2.237 & 5.095 & 1.536 \\
$\delta$ & $(3.772)$ & $(4.468)$ & $(2.135)$ \\
& & & 0.584 \\
$\kappa_{s}$ & & & $(1.633)$ \\
& $(1.462$ & $\mathbf{1 . 9 0 6}$ & $\mathbf{0 . 9 5 3}$ \\
$\kappa_{l}$ & -0.306 & -1.155 & 0.177 \\
& $-(0.136)$ & $-(1.011)$ & $(0.524)$ \\
$\lambda$ & 0.978 & 0.824 & 1.000 \\
& $(3.527)$ & $(2.953)$ & $(3.181)$ \\
F-stat & 1.36 & 11.49 & 16.87 \\
F-stat (CV) & 3.454 & 3.243 & 3.087 \\
DW Statistic & 1.739 & 1.932 & 1.413 \\
Adjusted $R^{2}$ & 0.995 & 0.999 & 0.999 \\
\hline \hline
\end{tabular}


Table 6: Policy Rules for the Norges Bank from 2005 - 2011 (1Q \& 2Q Forecasts). Table reports the estimated parameters from the policy rule in Bernhardsen (2008) (column B), the rule by Clarida et al. (1999) (column CGG) and the Calvo-type rule by Levine et al. (2007) (column Calvo). All specifications are estimated without and with interest rate forecasts, whereas the short-horizon forecast is $s=1$ (3 months) and the long-range forecast is $l=2$ (6 months). Reported t-statistics (in brackets) are calculated using asymptotic standard errors. The remaining rows report F-statistic (F-stat), Durbin-Watson statistic (DW) and adjusted R-squared, and the number of observations is 23 .

\begin{tabular}{cccc}
\hline \hline & B & CGG & Calvo \\
& $s=1, l=2$ & $s=1, l=2$ & $s=1, l=2$ \\
\hline$\gamma^{\pi}$ & 0.558 & 1.507 & 1.092 \\
$\gamma^{i n t}$ & $(1.036)$ & $(1.997)$ & $(1.622)$ \\
& 0.950 & & \\
$\gamma^{w}$ & $(2.413)$ & & \\
& 0.598 & & \\
$\gamma^{y}$ & $(1.069)$ & & \\
& 0.200 & 1.409 & 0.748 \\
$\varphi$ & $(0.522)$ & $(4.589)$ & $(2.578)$ \\
& -0.055 & 1.668 & 2.898 \\
$\delta$ & $-(0.115)$ & $(2.129)$ & $(6.682)$ \\
& & & -0.577 \\
$\kappa_{s}$ & 0.250 & $\mathbf{1 . 0 1 7}$ & $-(5.493)$ \\
& $(1.135)$ & $(4.205)$ & $(3.281)$ \\
$\kappa_{l}$ & 0.527 & -0.213 & $\mathbf{1 . 0 5 0}$ \\
& $(1.567)$ & $-(0.480)$ & $(2.558)$ \\
$\lambda$ & 0.872 & 0.051 & -0.028 \\
& $(2.278)$ & $(0.129)$ & $-(0.043)$ \\
F-stat & 16.98 & 94.87 & 128.95 \\
F-stat (CV) & 4.004 & 4.102 & 4.026 \\
DW Statistic & 1.669 & 1.932 & 1.824 \\
Adjusted $R^{2}$ & 0.995 & 0.999 & 0.999 \\
\hline \hline
\end{tabular}


Table 7: Estimated Taylor Rule on Simulated Data. Table illustrates the calibration of the model in Section 4.4.1 (upper panel) and the estimated parameters of the policy rule (15) without and with the interest rate forecast term (lower panel), whereas t-statistics (in brackets) are calculated using standard errors from the Monte Carlo simulation. The average values of Durbin-Watson statistic (DW) and adjusted R-squared are also reported, whereas every generated sample contains 60 observations and we simulate the model 3,000 times.

\begin{tabular}{|c|c|c|c|c|c|c|}
\hline & \multirow{2}{*}{\multicolumn{4}{|c|}{ Calibration }} & & \\
\hline & & & & & & \\
\hline & \multirow{2}{*}{\multicolumn{3}{|c|}{ NK Phillips Curve: }} & $=0.99$ & & \\
\hline & & & & $\lambda=0.3$ & & \\
\hline & \multicolumn{3}{|c|}{ IS curve: } & $\sigma=1$ & & \\
\hline & \multirow{2}{*}{\multicolumn{3}{|c|}{ Cost-Push Shock: }} & \multirow{2}{*}{$\begin{array}{c}\rho_{\chi}=0.9 \\
\sigma_{\chi}=1\end{array}$} & & \\
\hline & & & & & & \\
\hline & \multirow{2}{*}{\multicolumn{3}{|c|}{ Demand Shock: }} & $\rho_{\omega}=0.9$ & & \\
\hline & & & & $\sigma_{\omega}=1$ & & \\
\hline & \multirow{2}{*}{\multicolumn{3}{|c|}{ Loss-Function: }} & \multirow{2}{*}{$\begin{array}{l}a=0.3 \\
b=0.2\end{array}$} & & \\
\hline & & & & & & \\
\hline & \multicolumn{2}{|c|}{$c=10^{-7}$} & \multicolumn{2}{|c|}{$c=0.1$} & \multicolumn{2}{|c|}{$c=0.2$} \\
\hline & without & with & without & with & without & with \\
\hline \multirow[t]{2}{*}{$\gamma^{\pi}$} & 1.394 & 1.393 & 0.196 & 0.240 & 0.691 & 0.620 \\
\hline & $(1.241)$ & $(1.231)$ & $(0.852)$ & $(0.948)$ & $(4.247)$ & $(3.271)$ \\
\hline \multirow[t]{2}{*}{$\gamma^{y}$} & 0.566 & 0.564 & 0.605 & 0.635 & 0.075 & 0.032 \\
\hline & $(0.616)$ & $(0.609)$ & $(5.000)$ & $(4.677)$ & $(1.202)$ & $(0.413)$ \\
\hline \multirow[t]{2}{*}{$\rho_{1}$} & & -0.016 & & 0.100 & & 0.120 \\
\hline & & $(-0.113)$ & & $(1.212)$ & & (1.677) \\
\hline \multirow[t]{2}{*}{$\lambda$} & 0.888 & 0.889 & 0.928 & 0.938 & 0.920 & 0.934 \\
\hline & $(12.77)$ & $(12.64)$ & $(20.88)$ & $(24.95)$ & $(18.77)$ & $(22.95)$ \\
\hline DW Statistic & 1.955 & 1.952 & 1.329 & 1.170 & 1.400 & 1.174 \\
\hline Adjusted $R^{2}$ & 0.835 & 0.837 & 0.879 & 0.884 & 0.859 & 0.868 \\
\hline
\end{tabular}


Table 8: Estimated Taylor Rule on Simulated Data when the Rule is Misspecified. Table illustrates the calibration of the model in Section 4.4.1 (upper panel) and the estimated parameters of the policy rule (15) when the output gap term is excluded (lower panel). t-statistics (in brackets) are calculated using standard errors from the Monte Carlo simulation. The average values of Durbin-Watson statistic (DW) and adjusted R-squared are also reported, whereas every generated sample contains 60 observations and we simulate the model 3,000 times.

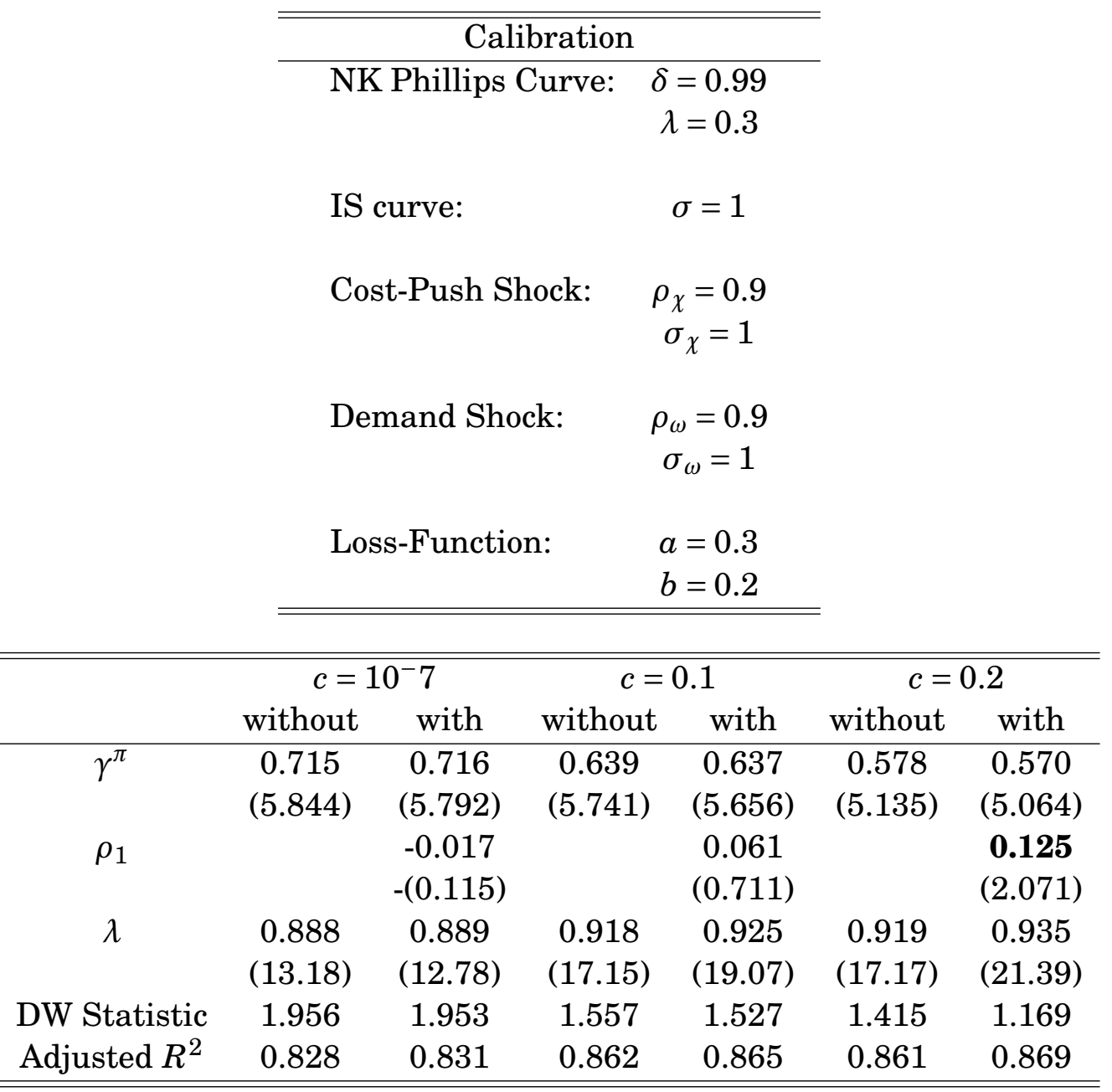


Table 9: Placebo Test. Table reports the estimated parameters from the policy rule specified in equation (17) for the Bank of England (2001 - 2009) and the Norges Bank (1999 - 2004). In both cases, the rule is estimated without and with the 3-month forward rate. t-statistics (in brackets) are calculated using asymptotic standard errors. The remaining rows provide F-statistic (F-stat), Durbin-Watson statistic (DW) and adjusted R-squared.

\begin{tabular}{ccccc}
\hline \hline & \multicolumn{2}{c}{ Bank of England } & \multicolumn{2}{c}{ Norges Bank } \\
& without & with & without & with \\
\hline$\gamma^{\pi}$ & 0.043 & 1.013 & 3.717 & 4.426 \\
& $(0.283)$ & $(0.304)$ & $(12.76)$ & $(3.141)$ \\
$\gamma^{y}$ & 0.875 & 2.200 & 0.717 & 0.574 \\
& $(9.425)$ & $(1.609)$ & $(6.283)$ & $(0.934)$ \\
$\varphi$ & 1.954 & 1.954 & 2.721 & 2.721 \\
& $(8.590)$ & $(1.234)$ & $(12.54)$ & $(1.546)$ \\
$\kappa_{1}^{E}$ & & 3.064 & & 0.395 \\
& & $(1.621)$ & & $(0.997)$ \\
$\lambda$ & 0.163 & 0.584 & 0.128 & 0.098 \\
& $(1.115)$ & $(0.723)$ & $(0.658)$ & $(0.087)$ \\
F-stat & 14.18 & 6.81 & 54.90 & 52.87 \\
F-stat (CV) & 4.018 & 3.725 & 4.500 & 4.248 \\
DW Statistic & 1.950 & 1.965 & 1.641 & 1.673 \\
Adjusted $R^{2}$ & 0.998 & 0.996 & 0.999 & 0.999 \\
N.Obs. & 34 & 34 & 23 & 23 \\
\hline \hline
\end{tabular}

